\title{
UNDERSTANDING THE CONCEPTUAL OF BUILDING INFORMATION MODELING: A LITERATURE REVIEW
}

\author{
Ibrahim Moh'd A.Q Saraireh \\ $\mathrm{PhD}$, Faculty of Civil Engineering, Universiti Malaysia Pahang, \\ 26300 Gambang Kuantan, Pahang, Malaysia \\ Ahmad Tarmizi Haron \\ Faculty of Civil Engineering, Universiti Malaysia Pahang, \\ 26300 Gambang Kuantan, Pahang, Malaysia
}

\begin{abstract}
Among the last decade there is several developments in the architecture, engineering, and construction (AEC) industry, information technology and its application was the major one. Building Information Modeling (BIM) is now globally considered a better solution to enormous building problems, it made huge effect on building and construction industry, and not only in the project design and implementation phases, but it is considered as a good tool for the whole project lifecycle. This paper aims to explain the concept of BIM including the definition, history, benefits and advantages. A conceptual understanding of (BIM) has been suggested in this paper depend on an extensive literature review. It is hoped that the concept emphasize in this paper will encourage positive debate on BIM and winning some concern from the practitioners and researchers.
\end{abstract}

Keywords: Building Information Modelling, AEC, literature review, Concept.

Cite this Article: Ibrahim Moh'd A.Q Saraireh, Ahmad Tarmizi Haron, Understanding the Conceptual of Building Information Modeling: A Literature Review. International Journal of Civil Engineering and Technology 11(1), 2020, 165-171.

http://iaeme.com/Home/issue/IJCIET?Volume=11\&Issue=1

\section{INTRODUCTION}

The construction industry has become more complicated and difficult to manage, because of low investment rate, raising cost, adding risk, and waste and labour productivity tremendously increase in this industry, this is confirmed by (Haron, 2013). So (BIM) is attractive solution and its main objective is the managing of the information, and all building problems. This study includes a background on building information modeling (BIM), its importance for the building industry. (BIM) is considering one of the most promising recent developments in the 
architecture, engineering, and construction (AEC) industry. With BIM technology, an accurate virtual model of a building is digitally constructed. This model, known as a building information model, it can be used for planning, design, construction, and operation of the facility. The model helps (AEC) to visualize what is to be built in a simulated environment to identify any potential design, construction, or operational issues. BIM represents a new paradigm within AEC, one that encourages integration of the roles of all stakeholders on a project.(BIM) provides close collaboration through project stakeholders to visualize what is to be built in a simulated environment by identifying any potential design, construction or operational issues (Ahmad Huzaimi, Mohamad Syazli,2017). BIM process can boost knowledge sharing for information of a building or facility. It forms a strong fundamental for decision making among the life cycle phase from the conceptual design to demolition (Azhar et al., 2015)

\section{LITERATURE REVIEW}

Building Information Modeling (BIM) has become the essential methodology including the digitalization of the built environment supply chain. BIM is a digital representation of the physical and functional characteristics of a building and serves as a knowledge sharing vehicle for building information (Barlish and Sullivan, 2012). Incentives and use related to BIM have been increasing over the past few years and received considerable recognition for its ability to reduce costs and time as well as improve quality (Juan et al., 2017). Azhar et al. (2015) demonstrates; "BIM has gone from being a buzzword to the centerpiece of AEC3 technology". Although BIM is applied to many large design and construction projects it is still not common practice throughout the industry. Now, design and construction projects are more efficient in terms of cost reduction, quality improvement, time schedule and a better work flow between project participants. In addition, project owners have started realizing other benefits deriving from BIM as a work method, such: as reduce claims, enabling easier calculations and visualizations for promotional purposes and ease of cross-disciplinary collaboration to name a few (Sanchez and Joske, 2016; McGraw Hill Construction, 2014).

\subsection{Definition of BIM}

The definition of building information modeling conception depends on the understanding of a researcher. BIM is not software as many people in the construction industry think. The BIM definition is in the form of using three-dimensional (3D) data in the process of producing and managing building data during its lifecycle, with appropriate building information software to improve productivity in building design and construction (Dan, 2015).

There are several aspects of BIM such as building geometry, spatial relationships, geographic information, quantities, and properties of building components are also produced from the process. According to Succar (2009) who clarified that BIM is a digital format to organize the appropriate building design and project data throughout the building's life-cycle. It can be concluded that BIM is a process to produce the digital information models (3D) with their relevant software in enhancing communication and interaction throughout the stakeholders.

There are many definitions and explanations for building information modeling have been introduced. Laiserin indicated that BIM is a process and not a software (Laiserin, 2017), while Woo described BIM as a new methodology for building design and documentation that provides faster and easier construction process for all involved parties(Woo,2006). Similarly, (Penttila, 2006) defined BIM as a methodology but for managing the digital format of design and project data during the building lifecycle. (Eastman et al., 2011) defined BIM as a technology that allows the building digital and virtual models to support design process 
phases by the accurate geometry and data. This not only will support the fabrication, procurement and construction phases but also will be used for other phases and activities of the building lifecycle. Thus, BIM can facilitate a form of integrated design and process that marks higher quality and reduces costs and time of the project. Furthermore, in 2007 the US National Building Information Modeling Standard (NBIMS) defined BIM as "BIM is a digital representation of physical and functional characteristics of a facility. (Azhar, 2011) expressed BIM as a pattern within AEC in which it can boost integration of all stakeholders on a project.

\subsection{BIM History}

BIM started in the 1950s and 1960s with the application of computer-aided design (CAD), after that CAD software is developed in 1963 by Ivan Sutherland by creating a graphical interface named Sketchpad, in 1970s by the French Aerospace Company who developed two dimensions (2D) to three dimensions (3D).

Subsequent, in the 1980s to 1990s, Autodesk become a popular developer and leading in the information technology (IT) industry with their product AutoCAD. The transformation From 3D model to the 4D model was introduced to help stakeholders, especially in the AEC industry in managing schedules and resources with respect to time. Later, 5D was developed to relate to cost estimating. This $5 \mathrm{D}$ model is valuable to cost estimators or quantity surveyors in checking the estimated cost of projects. The development of $6 \mathrm{D}$ is related to sustainability and 7D more to facilities management. However, the development of $\mathrm{nD}$ is dependent on the functions. As mentioned by (Beveridge, 2012), 8D was identified as integrated project delivery and maintainability, 9D for acoustics, 10D for security, and 11D was for heat. This shows that the transition of BIM started in the 1950s and continues to the present day.

\subsection{BIM benefits for Construction Industry}

BIM Benefits adapted from (Azhar, Khalfan, \& Maqsood, 2012) as following :

\section{Owner}

- Ensure that the project requirements are met from the early design stage.

- Evaluate the building performance and maintainability.

- Reducing financial risk due to reliable cost estimates and reducing the number of change orders.

- Best project marketing through the efficient use of 3D presentations and animation.

- Perfect and integral information about building and its systems in a single file.

\section{Designer}

- Better design by carefully analyzing digital models and visual simulations and receiving more valuable input from project owners.

- An early blend of sustainability features in building design to anticipate its environmental performance.

\section{Contractor}

- Better cost estimation and production.

- Discovering of design errors in early stage through clash detections.

- Construction planning and constructability analysis.

- Site safety planning.

- Favorite communication with stakeholders on site and high profitability.

- Preferable customer service.

- Compression the cost and schedule. 
- Best planning, management and informed decision making.

\section{Facility Managers}

- Major and essential information is found in one electronic file.

- BIM system and its database provide all information about any equipment in the project in just one click. So, the facility managers do not have to travel among the piles of information to gather data.

\section{Barriers to BIM Adoption}

The main disadvantages of BIM .as following :

- Contracting companies need to purchase and install appropriate hardware and software.

- Culture to resistance.

- Standards

- Before everything staff must trained to learn using the software, the new adopted technologies (Rajendran and Clarke, 2011).

- Various parties in the project who may use several software's and tools through the information exchange. This difference causes difficulty in exchange of the model because the software difference may describe information differently (Man, 2007).

\subsection{BIM for Sustainable Design}

BIM can supported sustainable design through (Wong \& Zhou, 2015), (Jrade \& Jalaei , 2013), (Dowsett \& Harty, 2013):

- Selecting the preferable building orientation that can minimize the energy cost.

- Managing the internal ventilation temperature.

- Analyzing the day lighting and the safety structural.

- Reducing the water needs in the buildings among construction or operation (Water harvesting).

- Selection of sustainable materials and reduce the construction waste energy needs.

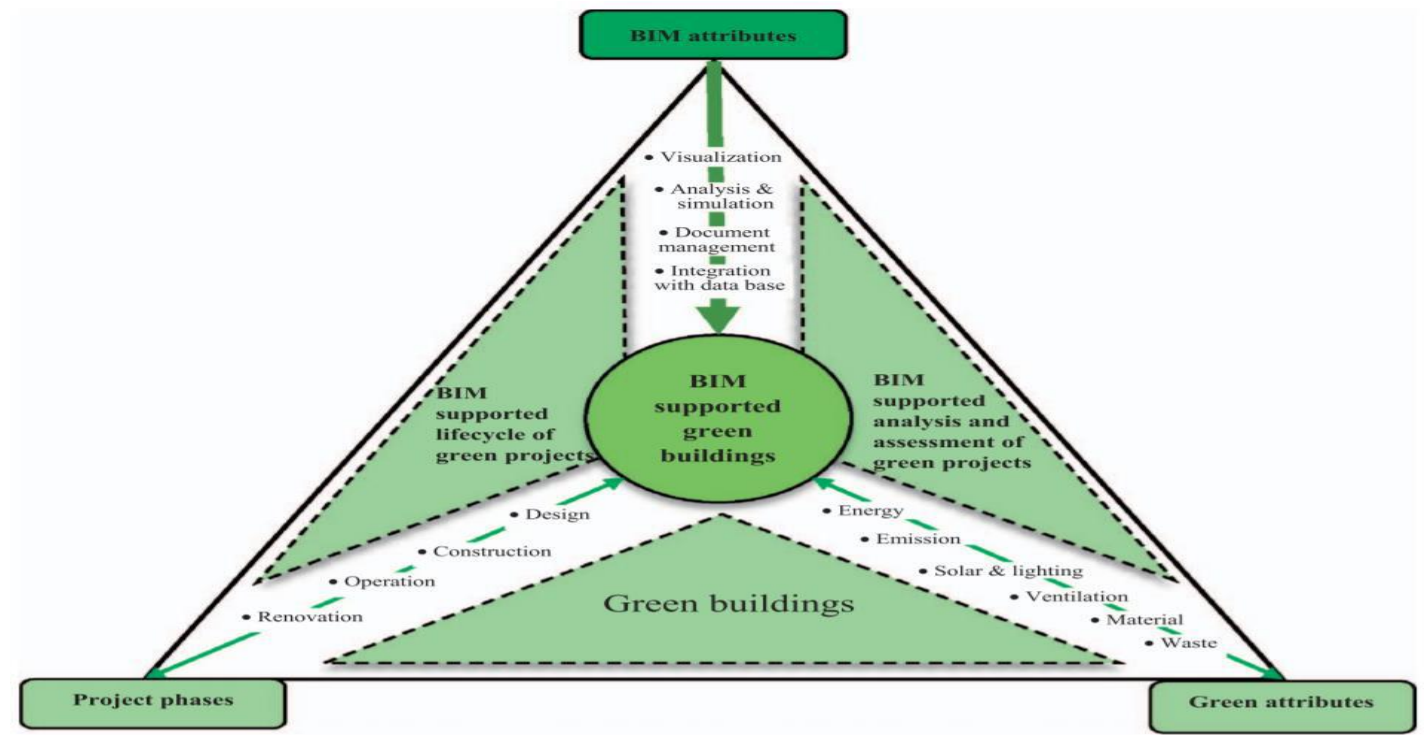

Figure 1 Green building BIM Triangle taxonomy (Lu, Wu, Chang, \& Li, 2017)

On the other hand, green BIM triangle which developed by ( $\mathrm{Lu}, \mathrm{Wu}$, Chang, \& $\mathrm{Li}, 2017$ ) explaining the interaction between BIM and green buildings and how BIM supports green buildings in several stages during the whole building lifecycle as shown in Figure 1. The 
green buildings according to the triangle divided into three major elements: the project stage, green attributes, and BIM attributes. The project phase contains the perspective of the project lifecycle (project design, construction, maintenance and operation, and demolition). The project attributes includes sustainability considerations such as energy saving, water saving, material selection, waste materials, day lighting, natural ventilation and acoustics analysis. The BIM attributes explain how BIM software contributes to the two green building elements by analysis, simulation and visualization, and interaction database.

\subsection{The Standard BIM Maturity Classification}

\section{BIM Phase 1 (Level 0-1)}

This explains the development from unmanaged to managed Computer Aided Design (CAD), both in 2D or 3D formats. At this phase, project teams are engaged with industry standards and processes such as the BS1192 in completely individualized or non-connected data and software systems (PAS1192:2, 2013). This may include stand-alone, design, engineering, communication, finance, or cost management packages (Succar, 2010).

\section{BIM Phase 2 (Level 2)}

This phase refers to the 3D model-based cooperation visualized as the main form of data management (Succar, 2010). This will, however, be depend on data produced and held in separate discipline based proprietary tools (Succar et al., 2012). The standards required for their production should however allow high degrees of interoperability, object based with sufficient levels of information detail and parameterization (PAS1192:2, 2013). Integration at this stage can be achieved through proprietary interface or bespoke middleware (Succar, 2010).

\section{BIM Phase 3 (Level 3)}

This phase explain the maturity level where network-based integration is to be achieved with the aid of fully open and interoperable processes enabled by standards, such as Industry Foundation Class (IFC) (Succar, 2009). The available commercial BIM software applications already possess such IFC data exchange capabilities (such as Autodesk Revit, Archicad, Vico, Bentley Micro Station), though the extent to which they are fully utilized is not clear, data and information is managed by a collaborative single platform model server with functionality that supports every CSC discipline's data uses (PAS1192:2, 2013). The progression of BIM maturity is depicted in Figure 2.

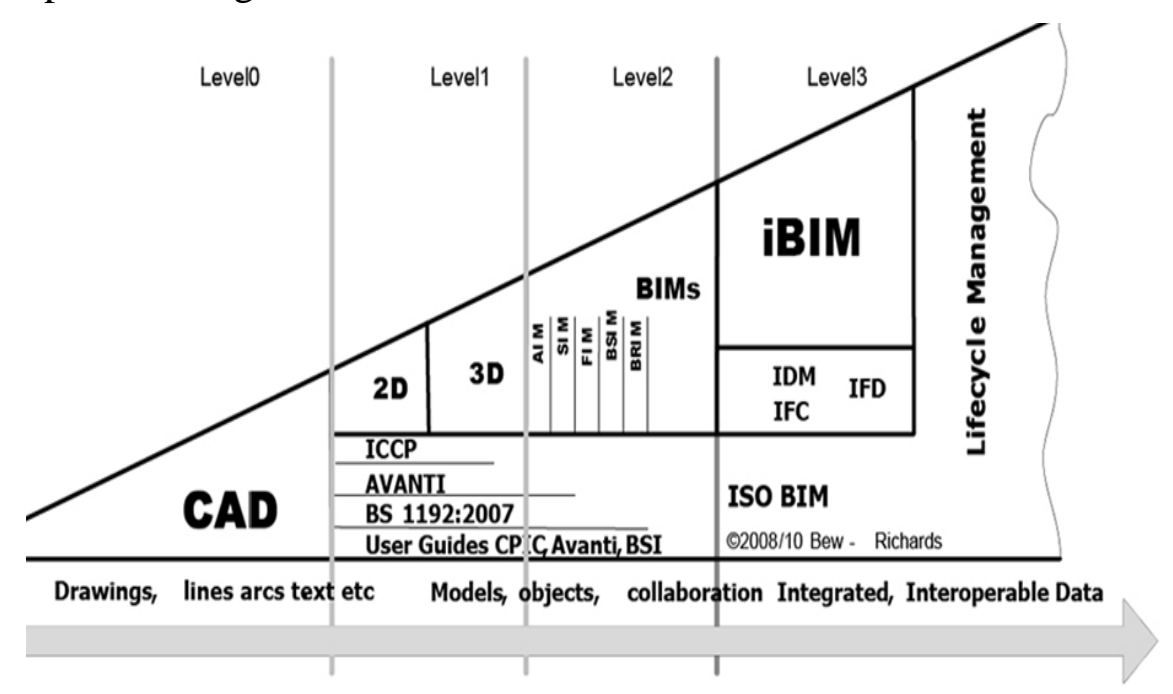

Figure 2: Development through BIM Maturity and Relevant Standards and Documentation (Bew et al., 2008) 
BIM level 2 implementation, as visualized by Government, will require all project information to be managed in a 3D virtual environment, where individual Construction Supply Chain(CSC) disciplines contribute data with proprietary tools that have high interoperable data exchange capabilities, that are supported by project data exchange protocol and standards (PAS1192:2, 2013). BIM Level 3 maturity explains entire system interaction, among single model server platforms where individual CSC contribute to projects in common or completely synchronized data environments (PAS1192:2, 2013).

\section{CONCLUSION}

In a summary, BIM supply a best platform for the AEC industry as it is able to improve the communication through the stake holders, collaboration and avoid fragmentation. Understanding of the concept of BIM is essential to assist stakeholders in the AEC industry to adopt and implement BIM. In addition, the resistance to change from the stakeholders is also a vital element in achieving this mission.

\section{REFERENCES}

[1] Azhar, S., Behringer, A., Sattineni, A., \& Maqsood, T. (2012). BIM for Facilitating Construction Safety Planning and Management at Jobsites. CIB-W099 International Conference: Modelling and Building Safety. Singapore.

[2] Azhar, S. (2011, July). Building Information Modeling (BIM): Trends, Benefits, Risks, and Challenges for the AEC Industry. Leadership and Management in Engineering, 11(3).

[3] Azhar, Salman, Malik Khalfan, and Tayyab Maqsood. "Building information modelling (BIM): now and beyond." Construction Economics and Building 12, n.o. 4 (2015): 15-28.

[4] Azhar, S., Khalfan, M., \& Maqsood, T. (2012). Building Information Modeling (BIM): Now and Beyond. Australasian Journal of Construction Economics and Building, 12(4), $15-28$

[5] Barlish, K. and Sullivan, K., (2012), How to Measure the Benefits of BIM - A case study approach. Automation in Construction, 24(1), 149-159.

[6] Beveridge, S. (2012). Best Practices using BIM in Commercial Construction, (December).

[7] BIS (2011) Government Construction Strategy. London, UK: Department of Business and Innovation .

[8] BIS (2013a) Industrial Strategy: Government and Industry in Partnership: Construction 2025. Report number: URN BIS/13/955.London, UK: Department for Business, Innovation and Skills.

[9] Dan, Z. (2015). An analysis of Building Information Modelling ( BIM ) implementation from a planned behavior perspective. Postgraduate Thesis University of Hong Kong, Pokfulam, Hong Kong SAR. Retrieved from http://dx.doi.org/10.5353/th_b5446484 .

[10] Dowsett, R. M., \& Harty, C. F. (2013). Evaluating the Benefits of BIM for Sustainable Design: A Review. Proceedings 29th Annual Association of Researchers in Construction Management Conference, ARCOM, (pp. 13-23). UK.

[11] Eastman, C., Teicholz P., Sacks R. and Liston K., BIM Handbook - A Guide to Building Information Modeling for Owners, Managers, Designers, Engineers, and Contractors, 2nd Ed. John Wiley \& Sons, Inc., 2011.

[12] Jamil H.A. Ahmad and Fathi S. Mohamad. An overview of contract documents for building information modelling (BIM) construction projects, Journal of Advanced Research in Business and Management Studies 7, Issue 2 (2017) 68-72 . 
[13] Jrade, A., \& Jalaei , F. (2013). Integrating Building Information Modelling with Sustainability to Design Building Projects at the Conceptual Stage. Building Simulation, 6, 429-444.

[14] Haron, A. T. (2013). Organisational readiness to implement building information modelling: A framework for design consultants in Malysia, University of Salford.

[15] Laiserin, J. To BIMfinity and Beyond! (AEC Insight Column), Building information modeling for today and tomorrow. On-line: http://www.cadalyst.com/aec/to-bimfinityand-beyond-aec-insight-column-3686, Accessed: 01/09/2017.

[16] Lu, Y., Wu, Z., Chang, R., \& Li, Y. (2017). Building Information Modeling (BIM) for Green Buildings: A Critical Review and Future Direction. Automation in Construction, 83, 134-148.

[17] Man, M. (2007). BIM, Building Information Modeling and Estimation, Stockholm: Byggteknik och design, Kungliga tekniska högskolan. Rajendran, S., \& Clarke, B. (2011). Safety Benefits and Opportunities.

[18] NIBS, The National Building Information Model Standard (NBIMS). American National Institute of Building Sciences, 2007.

[19] Succar, B. (2009). Building information modelling framework: A esearch and delivery foundation for industry stakeholders. Automation in Construction, 18(3), 357-375.

[20] Succar, B. (2010) Building Information Modelling Maturity Matrix. Handbook of Research on Building Information Modeling and Construction Informatics: Concepts and Technologies. IGI, pp.65-103.

[21] Succar, B., Sher, W. and Williams, A. (2012) Measuring BIM Performance: Five metrics. Architectural Engineering and Design Management, 8 (2), pp.120-142.

[22] Succar, B. (2009) Building Information Modelling Framework: A Research and Delivery Foundation for Industry Stakeholders. Automation in Construction, 18 (3), pp.357-375.

[23] Penttilä, H., Describing the changes in architectural information technology to understand design complexity and free-form architectural expression. Journal of Information Technology in Construction (ITcon), 11:395-408, 2006.

[24] Wong , J., \& Zhou, J. (2015). Enhancing Environmental Sustainability Over Building Life Cycles Through Green BIM: A Review. Automation in Construction, 57, 156-165.

[25] Woo, J.H. BIM (Building Information Modeling) and Pedagogical Challenges. In Proceedings of the 43rd ASC National Annual Conference, 2006. 